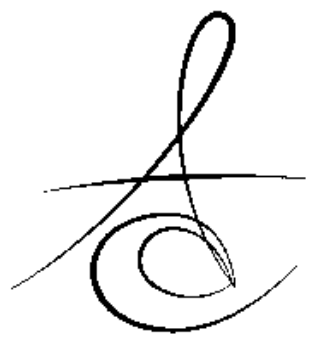

\title{
KISMİ MAKSİLLEKTOMİ YAPILMIŞ HASTALARIN BUKKAL UZANTILI OBTURATÖR İLE PROTETİK REHABİLITTASYONU: VAKA RAPORU
}

\section{PROSTHETIC REHABILITATION OF PATIENTS WITH BUCCAL FLANGE OBTURATOR AFTER HEMIMAXILLECTOMY: CASE REPORT}

\author{
Dt. Canan AKAY* \\ Prof. Dr. Suat YALUĞ*
}

Makale Kodu/Article code: 1339

Makale Gönderilme tarihi; 01.10 .2013

Kabul Tarihi: 31.10.2013

\section{ÖZET}

Maksillektomi yapılmış olan hastalar; estetik, fonetik, fonksiyonel, psikolojik birçok sorunla karşı karşıyadırlar. Hastaların tedavisi oldukça zor ve zahmetlidir. Bunun için değişik tedavi alternatifleri mevcuttur. Tedavilerin her birinin avantaj ve dezavantajları bulunmaktadır. Protetik rehabilitasyonun birincil amacı maksiller defekti kapatmak ve problemleri ortadan kaldırmaktır. Cerrahi tekniklerin yetersiz kaldığı durumlarda obturatör, en iyi tedavi seçeneğidir. Doğru bir tedavi için hastalığın etiyolojisi, klinik bulguları ve prognozu bir bütün içinde değerlendirilmeli ve iyi bir teknik uygulanmalıdır. Bu makalede de tümoral nedenler sonucunda maksiller rezeksiyon yapılan iki hastanın obturatör ile protetik rehabilitasyonu anlatılmaktadır.

Anahtar kelimeler: Obturatör, maksiller defekt, maksillofasial protez, bukkal uzantılı obturatör

\section{GİRIŞ}

Malinite gösteren oluşumların yaklaşık olarak $\% 5$ i oral ve maksillofasiyal bölgede ${ }^{1}$, oral bölgede görülen malinitelerin de \% 9 kadarı sert damak ta ve $\% 12$ si de dişetinde lokalize olmaktadır. Maksiller bölgede görülen malin oluşumların yıllık insidansı Amerika'da 1/100,000'den daha az olarak

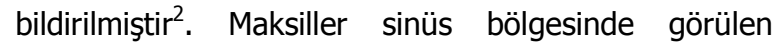
maliniteler sıkıkla squamoz hücreli karsinom, adenokarsinom, adenoid kistik karsinoma, tükrük bezi karsinomu ve malin melanoma'dır. Tedavi yöntemini ise cerrahi ve/veya radyoterapi oluşturmaktadır ${ }^{3}$. Yapılan cerrahi operasyonlar sonucunda malinitenin bulunduğu bölgede defekt oluşmaktadır.

\section{ABSTRACT}

Patients who underwent maxillectomy operation are faced with many problems like aesthetic, phonetic, functional, psychological. The treatment of patients is quite difficult and troublesome. Different treatment alternatives are available for maxillectomy patients. There are advantages and disadvantages of each treatments. The primarily aim of prosthetic rehabilitation is to cover the maxillary defect and eliminate the problems. The best treatment option is obturator when surgical techniques are not sufficient. Clinical findings etiology and prognosis of the case must be evaluated completely for exact treatment and suitable technique must be apply for treatment. In this article, rehabilitation with obturator prosthesis was explained for two patients subjected to maxillary resection at the end of tumoral reason.

Key words: Obturator, defect of maxilla, maxillofacial prothesis, buccal flange obturators

Defektin öncelikli olarak cerrahi olarak rehabilitasyonu düşünülmektedir fakat bu çoğu zaman mümkün olmamaktadır.

Stomatognatik yapıların veya ilgili yüz bileşenlerin eksiklik ve bozukluklarına çene yüz defekti denilmektedir. Çene yüz defektlerinin sabit ya da hareketli protezlerle restorasyonu ve rehabilitasyonu ile ilgilenen diş hekimliği dalına ise maksillofasial prostodonti adı verilir ${ }^{4}$.

Maksillofasial defektler sonucunda oroantral komünikasyonun bozulmasıyla birlikte çiğneme yutkunma, konuşma bozulur, yüz bölgesinde düzensizlikler oluşur. Protez uzmanı mevcut defektlerin obturatör ile rehabilitasyonunda önemli rol oynar.

${ }^{1 *}$ Gazi Üniversitesi Diş Hekimliği Fakültesi Protetik Diş Tedavisi Anabilim Dalı 
Maksiller defektler sonucunda oroantral komünikasyonun bozulmasıyla çiğneme, konuşma zorlaşır, konuşma rezonansı bozulur ve yüzde asimetri gözlenir ${ }^{5}$. 'Obturatör' terimi latin kökenli 'Obturare' kelimesinden gelmekte olup tıkamak sözcüğünü ifade etmektedir. Diş hekimliğinde; benin ve malin tümörlerin cerrahi olarak rezeke edilmesi, konjenital malformasyonlar ve travmatik sebepler ile maksillanın kısmi ya da total olarak çıkartıması sonucu oluşan, oral ve nazal locaları birleştirerek birtakım komplikasyonlara yol açan ve cerrahi olarak kapatılamayan defektleri tıkayan apareylere obturatör denilmektedir.

Çene-yüz defektlerinin protetik tedavisi uzun yıllardır yapılmaktadır. İlk olarak 1500'lü yıllarda Ambrose Pare maksilla da bulunan bir defekti kapatmak için palatinal bir plak üzerine sünger parçasını tutturarak yaptığı aparey ile obturatör terimini kullanmıştır. Bu tarihten sonrada obturatör yapım kavramları ve yöntemleri geliştirilmiştir ${ }^{6,7}$.

Bu makalemizde tümoral sebepler sonucunda maksiller rezeksiyon yapılmış Aramany sınıflamasına göre sınıf 1 olan iki hastanın obturatör ile protetik rehabilitasyonu anlatılacaktır.

\section{OLGU BİLDİRİMİ}

\section{VAKA1}

Gazi Üniversitesi Diş Hekimliği Fakültesi Protetik Diş Tedavisi Anabilim Dalına başvuran 71 yaşındaki bay hastanın alınan anamnez ve kayıtlarında, 2010 yilında sol üst çenesinde tespit edilen $(4,5 \mathrm{~cm}$ genişlik ve $2.5 \mathrm{~cm}$ uzunluğa sahip) squamoz hücreli karsinomun cerrahi olarak çıkartıldığı, hastanın 2 ay kadar yatarak tedavi gördüğü ve son 1.5 ay süreyle radyoterapi uygulandığı belirlendi. Yapılan ağız içi muayenesinde hastaya sert damağı içeren sol total maksillektomi yapıldığı gözlendi.(Resim 1) Kısmi dişsizlik ve defekte bağlı olarak hastada çiğneme ve yutkunma güçlüğü, fonasyon bozukluğu, psikolojik çöküntü kaydedildi. Hastada oluşan problemleri gidermek, psikolojik olarak rahatlama sağlamak amacıyla hastaya bukkal uzantılı daimi obturatör protez yapımı planlandı. Ölçü alımından önce defekt bölgesi, aşırı andırkatlı bölgelere ölçü maddesinin kaçmasını önlemek ve ölçüde kopmalara neden olmamak için vazelinlenmiş gazı bez ile kapatıldı. Tahrişi önlemek amacıyla hastanın dudakları da vazelinlendi. Standart metal 2 numaralı dişli ölçü kaşığı yardımıyla üst çenenin anatomik ölçüsü irreversibıl hidrokolloid ölçü maddesi ile alındı. İlk modeller elde edildi. Elde edilen modeller ile kişisel akrilik ölçü kaşığı yapıldı. Hastanın ikinci ölçüsü de aljinat ile hastaya yanak ve dudaklarına çeşitli fonksiyonel hareketler yaptırılarak alındı. Ana model elde edildikten sonra kalan destek dişlerden de retansiyon ve stabilite için yararlanılmak amacıyla sağ ikinci premolar ve sağ ikinci molar dişe akers kroşe gelecek şekilde planlama yapılarak metal iskelet dökümü yapıldı. (Resim 2) Hasta ağzında prova edildikten sonra kapanış alınarak kapanışa uygun diş dizimi yapıldı ve hasta ağzında prova edildi. (Resim 3,4) Dişli provadan sonra bilinen yöntemlerle kaide maddesi olarak polimetilmetakrilat kullanılarak obtüratör tamamlandı. Obtüratörün rahat kullanımını sağlamak için defekt bölgesine uzanan bulb kısmının içi boşaltıı tesfiye ve cila işleminden sonra hastaya teslim edildi.(Resim 5) Tedavi bitiminden sonra hasta bir ay boyunca haftallk kontrollere çağırılarak protezin kontrolü yapılıp ufak vurukları alındı. Defekti çevreleyen kemik bölgesinde herhangi bir travmatik etkiye rastlanmadığı için, tutuculuk ve stabilite problemi de olmadığından yumuşak astar uygulamasına gerek görülmedi. Hasta bir yıllık takiptedir.

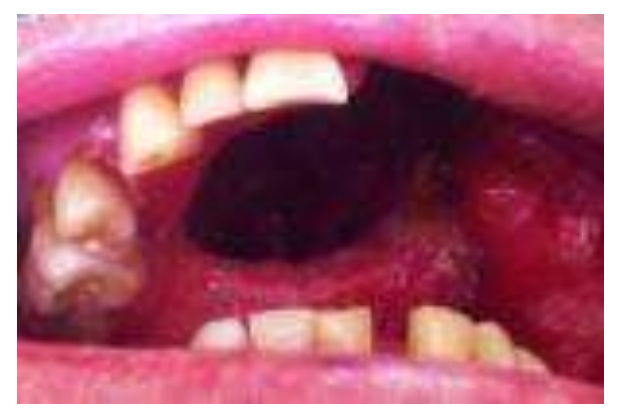

Resim 1. Vaka I' deki hastanın ağız içi görünümü.

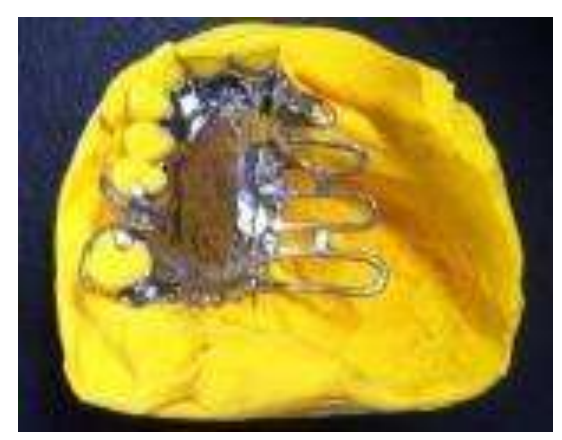

Resim2. Vaka I' deki hastanın iskelet dökümü. 


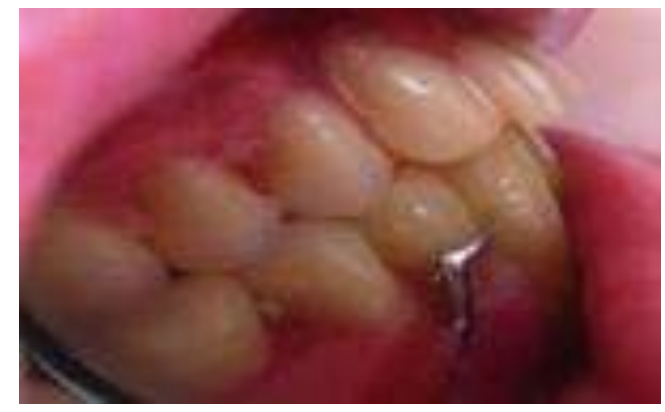

Resim3. Vaka I' deki hastanın dişli prova hasta ağzında kontrolü.

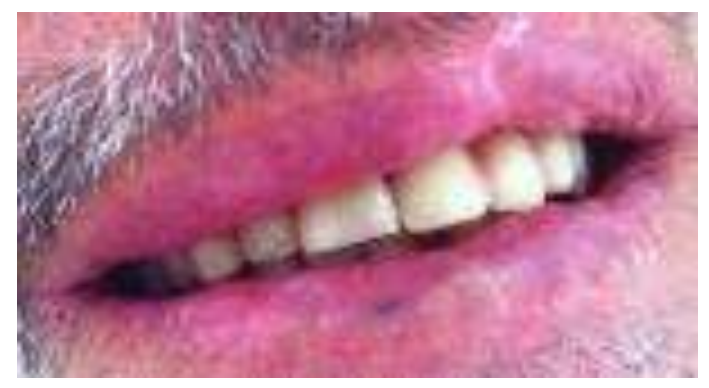

Resim 4. Vaka I' deki hastanın dişli prova kontrolü.

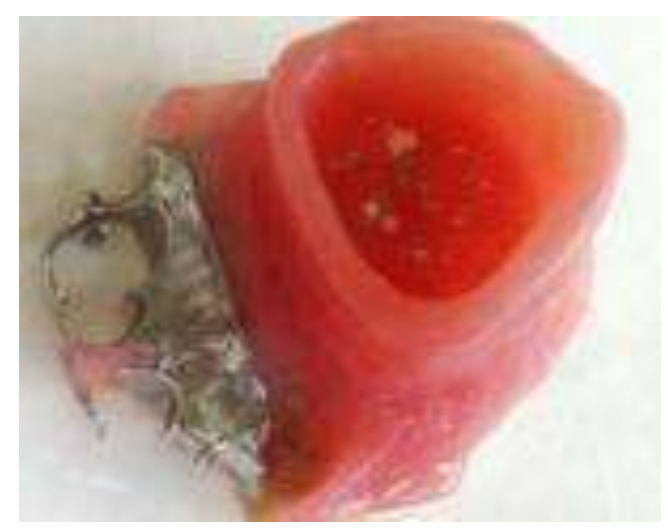

Resim 5. Vaka I' deki obtüratörün bitmiş görünümü.

\section{VAKA 2}

Gazi Üniversitesi Diş Hekimliği Fakültesi Protetik Diş Tedavisi Anabilim Dalına başvuran 64 yaşındaki bayan hastanın alınan anamnez ve kayıtlarında 2009 yılında sol üst alveolar arkta yirmi yaş dişini çektirdiği uzun süre yara yerinin kapanmadığı uygulanan lokal tedavilere rağmen şikayetinin geçmediği ve şüphelenilerek patoloji alınması üzerine kötü huylu tümör bulgusuna rastlanması sonucu, hastanın opere edilerek radyoterapi gördüğü belirlenmiştir. Düzenli gittiği kontrollerinde kitle tespit edilmemesine rağmen şikayeti devam eden hastadan daha sonra tekrar alınan biyopsi sonucuna göre epidermoid karsinom tesbit edilmiştir. Hasta ikinci kez opere edilmiş sol maksilla, orbita tabanı ve sol gözün rezeke edildiği belirlenmiştir. Hastanın ekstra oral estetik görünümünde bozukluk, konuşmada rezonans bozukluğu, çiğneme ve yutkunmada zorluklar mevcuttu. Hasta sosyal ve psikolojik anlamda da dış görünümünden rahatsızdı. Aramany sınıflamasına göre sınıf I olan vakada hastaya estetik, fonetik ve fonasyon iadesi için bukkal uzantılı obturatör yapımına karar verildi.

Ölçü almadan önce maksiller defektin andırkat içeren bölgeleri ve ölçü alımı esnasında hidrokolloid ölçü maddesinin ufak perforasyonlara girerek kopacağı düşünülen bölgeler vazelinli gazlı bez ile kapatıldı. Standart dişli metal ölçü kaşığının rezeke edilen bölgeye gelen kısmı pembe mum ile uzatılıp şekillendirildi. Aljinat ile ilk ölçüsü alındıktan sonra ilk modeller elde edildi. Bu modeller kullanılarak hasta ağzına uygun bireysel akrilik ölçü kaşığı hazırlandı. Akrilik kaşık ile fonksiyonel ikinci ölçü alınarak(Resim 1) model elde edildi. Kalan dişlerden destek olarak yararlanmak amacıyla sağ santral dişe diş eti, sağ birinci molar dişe akers kroşe geçirilecek şekilde iskelet dökümü yapıldı. İskelet model ağızda kontrol edildikten sonra pembe mum ile mum şablon yapılıp kapanış elde edildi ve diş dizimi yapıldı. Dişli prova hasta ağzında kontrol edildi.(Resim 2) Provadan sonra konvansiyonel protez bitim işlemlerine geçildi. Obturatör kaide materyali olarak polimetilmetakrilat kullanıldı. Akrilik tepimi ve polimerizasyonundan sonra defekt bölgesi ile temasta bulunan bulb kısmının içi protez ağırlığını azaltmak ve hastanın rahat kullanımını sağlamak için boşaltıldı. Boşaltılan kısmın üstü tekrar akrilik ile kapatılmadı. Obturatör hasta ağzında kontrol edilerek gerekli düzenlemeler yapıldıktan sonra hastaya protez kullanımı ve bakımı hakkında bilgi verilip teslim edildi.(Resim 3-4) Hastanın haftalık olarak düzenli kontrolleri yapıldı. Protezini rahat bir şekilde kullanan hastanın psikolojik olarak da rahatladığı gözlendi. Hasta yaklaşık bir yıllık takiptedir. Herhangi bir şikayeti bulunmamaktadır. 


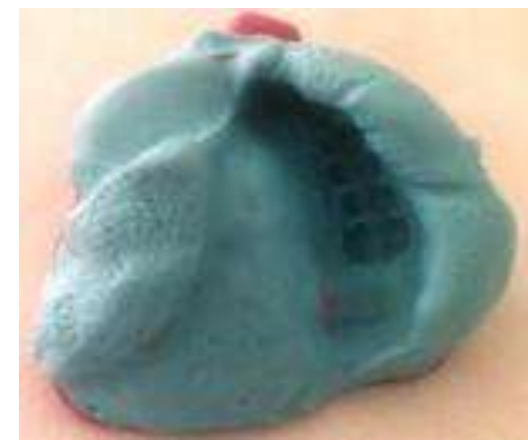

Resim 1. Vaka II' deki hastanın üst çenede defektli alanı da kapsayan esas ölçüsü.

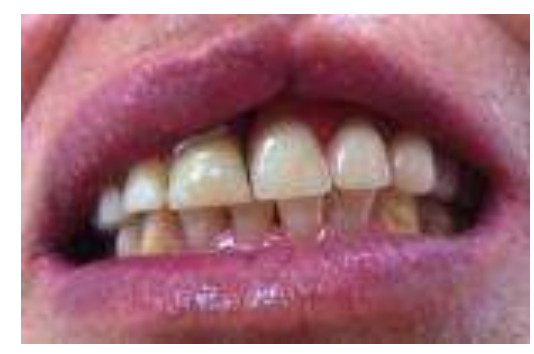

Resim 2. Vaka II' deki hastanın dişli prova kontrolü.

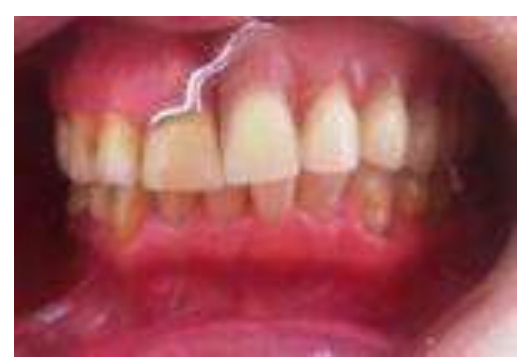

Resim 3. Vaka II' deki obtüratörün ağız içi görünümü.

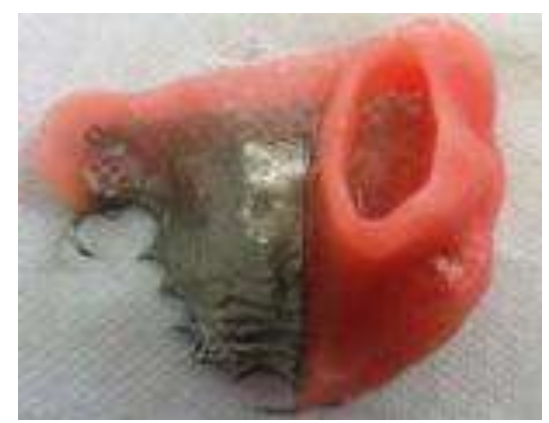

Resim 4. Vaka II' deki obtüratörün bitmiş halinin görüntüsü.

\section{TARTIŞMA}

Hastaların maksillektomi operasyonu ile kaybettikleri estetik fonksiyon ve fonasyonun iadesi için yapılan obtüratörler çeşitlilik göstermektedir. Obtüratör seçiminde defektin büyüklüğü, hastanın beklentileri ve sosyoekonomik durumu önemli rol oynamaktadır.

İçi boşaltılmadan yapılan obturatörler protez ağırlığını artırarak rehabilitasyonun başarısını düşürmektedir; bukkal uzantılı obtüratörler ise ağırlığı azaltması ve daha hijyenik olması gibi sebeplerle daha iyi bir seçenektir. İçi boş obtüratörlerin protez ağırığını \% 6.5-33.06 oranında hafiflettiği belirtilmektedir ${ }^{8}$. Obturatörün ağırlığı hafif olduğu için hasta fonksiyon esnasında daha rahat eder, yapay dişlere iletilecek olan yük az olacağından aşınma daha az olur, çevre dokularda oluşan stres azalır, protezin retansiyon ve stabilitesi artar, doku rejenerasyonu üzerine olumlu etkiler sağlar ${ }^{9}$.Kapalı hollow bulb obturatörler ise bu bölgede gıda ve sıvı birikimini önler, hava akışını azaltır $^{10}$.Hastaların çiğneme, yutkunma ve konuşma fonksiyonlarını sağlarlar. Ancak nazal rezonans odasını tıkadıkları için konuşma kalitesi bukkal uzantılı obturatörler kadar iyi değildir. Bukkal uzantılı obturatörlerin medial, lateral ön ve arka duvarları olmasına karşılık tavanının bulunmaması defekt içindeki rezonans odasını küçültmez ${ }^{7}$.Bu şekilde konuşma kalitesi de bozulmaz.

Sing ve arkadaşları ${ }^{10}$ Aramany sınıf 1 defekte sahip hastalarına yapmış oldukları hibrit obturatör ile hastanın konuşma ve çiğneme kalitesinin arttığını, obtüratör ağırlığının azaldığını, temizliğinin kolay yapılarak hijyenik olarak da üstün olduğunu savunmuşlardır. Biz iki tekniğin aynı anda kullanılmasının gereksiz olduğunu düşünerek tercih etmedik.

Depprich ve arkadaşlar ${ }^{11}$ ise maksiller defekte sahip hastalarda yapmış oldukları titanyum, silikon ve polimetilmetakrilat yüzeye sahip obturatör protezleri mikroorganizma tutulumu açısından değerlendirmişlerdir. Titanyum alaşımı kullanılarak yapılan obturatörlerin maksiller rezeksiyon sonrasındaki hastalarda lokal ya da sistemik enfeksiyon riskini düşürdüğü ve hastaları patojenik oral mikroorganizma oluşumuna karşı koruduğunu bildirmişlerdir. Titanyum alaşımdan yapılan obturatörde mikroorganizma tutulumunun az olması avantajıdır. Ancak maliyetinin fazla olması, oluşan vurukların alınma güçlüğü gibi dezavantajlara

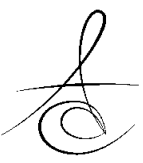


da sahiptir. Bizde bu sebepten dolayı titanyum alaşımı ile yapılan obturatörü tercih etmedik.

Parsiyel ya da total maksillektomi yapılmış hastaların protetik rehabilitasyonunda dental ya da zigomatik implantların yerleştirilmesi de protezin retansiyon ve stabilitesini anlamlı derecede artırır. Shirota ve arkadaşları ${ }^{12}$ bildirdikleri vaka raporunda maksiller defekte sahip hastaların protetik rehabilitasyonunda dental ve zigomatik implant kullanımının retansiyon ve stabiliteyi anlamlı ölçüde artırdığını ve oral fonksiyonları iyileştirdiğini belirtmişlerdir. Ancak zigomatik implantların zigomatik kemiğin kompleks yapısı ve operasyon esnasında görüş mesafesinin sınırlı olmasından dolayı uygulanmaları zordur, hastaya ikinci bir cerrahi işlem gerektirir ve maliyeti ağırdır ${ }^{13,14}$.Bizim vakalarımızda ise ağızda tutuculuk ve stabiliteye yardımcı olacak doğal dişlerin bulunması, ekonomik sebepler ve hastamızın yeniden bir cerrahi müdahaleye sıcak bakmamasından dolayı bu tedaviyi tercih etmedik.

\section{SONUÇ}

Maksillofasial defekte sahip olan hastalarda protez uzmanı sadece defektin kapatımasının ve yeterli retansiyonu sağlamanın yanında hastanın gelecekteki sosyal yaşantısı için konuşma, çiğneme, yutkunma fonksiyonlarının devamın sağlayan rahat ve estetik olarak kabul gören bir obturatör yapımını amaç edinmelidir.

\section{KAYNAKLAR}

1. Rieger J, Wolfaardt J, Seikaly $H$, Jha N. Speech outcomes in patients rehabilitated with maxillar $y$ obturator prostheses after maxillectomy: a prospective study. Int JProsthodont 2002;15: 13944.

2. Kreeft $A M$, Krap $M$, Wismeijer $D$, Speksnijder $C M$, Smeele LE, Bosch SD, Muijen MS, Balm AJ. Oral function after maxillectomy and reconstruction with an obturator. Int J Oral Maxillofac Surg 2012; Nov; 41:1387-92.

3. Itami J, Uno $T$, Aruga $M$, Ode $S$. Squamous cell carsinoma of the maxillary sinus treated with radiation therapy and concervative surgery. Cancer 1998; 82:104-7
4. Adisman IK. Prosthesis serviceability for acquir jaw defects. Dent Clin North Am. 1990;34:265-83

5. Buzayan MM, Ariffin YT,Yunus N. Closed hollow bulb obturatör- One stepfabrication: A clinical report. J Prosthodont 2013; 1-5

6. Korkmaz FM. Maksiller defektlerde kuvvet dağıımının uygulanan implantların tip ve lokalizasyonlarına göre sonlu elemanlar analizi yöntemiyle değerlendirilmesi. Doktora Tezi. Ankara: Gazi Üniversitesi; 2008

7. Yaluğ S,Nalbant L. Bir bukkal uzantılı obtüratör yapımı. Cumhuriyet Ünv. Diş Hek Fak Dergisi 1998;1: 78-80

8. Devlin $H$, Barker GR. Prothetic rehabilitation of the edentulous patient requiring a partial maxillectomy. J Prosthet Dent 1992; 67: 223-7

9. Özdemir H, Aladağ L.İ. Sonradan kazanılmış bir maksiller defektin protetik obturasyonu: Bir olgu sunumu. Atatürk Ünv Diş Hek Fak Derg 2011; Supplement 4: 122-7

10. Sing K, Sing S.V,Mishra N, Aagrawal K. K. Management of maxillectomy defect with a hybrid hollow bulb obturator. BMJ. Case Reports. 2013; 10: 1

11. Depprich RA, Handschel JG, Meyer U, Meissner G. Comparison of prevalence of microorganisms on titanium and silicone/polymethyl methacrylate obturators used for rehabilitation of maxillary defects. J Prosthet Dent 2008;99:400-5

12. Shirota T, Shimodaira O,Matsui $Y$, Shintani S. Zygoma implant-supported prosthetic rehabilitation of a patient with maxillary defect. Int J Oral Maxillofac Surg 2011; 40: 106-123

13. Kreissl ME, Heydecke G, Metzger MC, Schoen R. Zygoma implant- supported prosthetic rehabilitation after partial maxillectomy using surgical navigation: a clinical report. J Prosthet Dent 2007; 97: 121-8

14. Bedrossian E, Rangert B, Stumpel L, Indresano T. Immediate function with the zygomatic implant: a graftless solution for the patient with mild to advanced atrophy of the maxilla. Int J Oral Maxillofac Implants 2006; 21: 937-42.

\author{
Yazışma Adresi \\ Dt. Canan Akay \\ Gazi Üniversitesi , Diş Hekimliği Fakültesi \\ Protetik Diş Tedavisi Anabilim Dalı/ ANKARA \\ Telefon: 05303338626 \\ E-mail: cnngcr2@hotmail.com
}

